\title{
Community Driven Development of Rocket Stoves in Rural South Africa
}

\author{
Anne de Chastonay \\ Undergraduate, Urban \& Environmental \\ Planning and Global Development Studies \\ University of Virginia \\ Charlottesville, VA 22903 \\ acd7q@virginia.edu \\ Michael Bugas \\ Undergraduate, Global Development Studies \\ University of Virginia \\ Charlottesville, VA 22903 \\ mab3nx@virginia.edu
}

\author{
Shreya Soni \\ Undergraduate, Biomedical Engineering \\ University of Virginia \\ Charlottesville, VA 22903 \\ ss3mb@virginia.edu \\ Dr. Robert Swap \\ Professor, Department of Environmental Sciences \\ University of Virginia \\ Charlottesville, VA 22903 \\ rjs8g@email.virginia.edu
}

\begin{abstract}
This article details the process of the implementation of collaboratively developed, clean cookstove technology in rural Limpopo Province of South Africa. The stove design drew heavily upon existing, open source knowledge regarding top light updraft wood fired stoves and suggestions from on the ground practitioners in South Africa. Implementation followed the model of community engagement that values community assets and adheres to a platform of mutual respect and reciprocity as part of the relationship. The more than two year project evolved out of a more than a decade long series of personal, professional and institutional partnership between the students, faculty and community members from the University of Venda in South Africa and the University of Virginia in the U.S. The article not only details the design and build out phases of the affordable cookstoves, but also details the history and context of the collaborative student project.
\end{abstract}

Index Terms - Community Engagement, Rocket Stove, Service-learning, South Africa

\section{INTRODUCTION}

Stove Inefficiencies in the Developing World

Approximately 2.5 billion people worldwide depend on biomass energy as cooking fuel. ${ }^{\mathrm{i}}$ About 2 million of these people lose their lives each year due to stove-related respiratory illnesses, with women and children most at risk. ${ }^{\text {ii, iii }}$ Associated deforestation and greenhouse gas emissions also affect the natural environment in ways that are not yet completely understood and may have potentially catastrophic effects. Furthermore, cooking over an open fire is the most expensive way to cook with wood, and rural households in Sub-Saharan Africa dedicate 0.33 hours to 4 hours per day to harvesting biomass energy. ${ }^{\text {iv }}$ Inefficient biomass-burning cooking methods, such as cooking over open fire, may also pose severe health (elevated concentrations of inhalable particulate matter), environmental (overharvesting of fuel wood), and economic (considerable opportunity costs associated with fuel gathering and cooking) challenges. 
The good news is that more efficient cookstove technology can help address these issues. National Institute of Health researchers have stated that implementing better stove designs into the homes and communities of developing countries would drastically reduce the reoccurrence of phenomena and respiratory illnesses such as lung cancer, and chronic obstructive pulmonary disease. ${ }^{\mathrm{v} \text {, vi }}$ More efficient biomass cookstoves could improve combustion emissions by reducing particulate concentrations and warming by carbon dioxide emissions by 25 to 50 percent. ${ }^{\text {vii }}$ And lastly, the World Bank has determined that efficient cookstoves can reduce overall cooking expenditures by up to 40 percent compared to cooking over open fires, even when accounting for initial costs. viii

Thus, there is a well-documented need to develop and implement cleaner cooking alternatives to combat global health, environmental, and economic issues. To the broad potential of clean cookstoves, the United Nations created the Global Alliance for Clean Cookstoves, which is a "public-private partnership" seeking "to create a global market for clean and efficient cookstoves and fuels in the developing world." The target goal for this initiative is to bring 100 million stoves to the developing world by 2020 . $^{\text {ix }}$

\section{The Role of Community Engagement and Collaborative Service-Learning}

Practitioners who routinely engage resource limited communities recognize that the long-term success of solutions to challenges such as energy efficiency depends upon more than just the best technology; it depends upon "engaging people, not projects." ${ }^{x}$ This community engagement philosophy, based on mutual respect, reciprocal learning, and maintenance of relationships, drives the work of a collaborative institutional network that facilitates research, education, and outreach activities related to the environment in southern and eastern Africa. This network, the Eastern and Southern African and Virginia Networks and Associations (ESAVANA), involves faculty, students and community members from institutions of higher learning including: the University of Virginia (University of Virginia), the Universities of Venda, Johannesburg and the Witwatersrand-Johannesburg (S. Africa), the University of Botswana, and the University of Eduardo Mondlane (Mozambique). ${ }^{\mathrm{xi}}$

\section{Project Background}

In 2008, one ESAVANA partner community-based institutional partner, the Mashamba Presidential Primary School, located in the Vhembe district of the Limpopo Province of South Africa, raised the issue of stove inefficiencies in discussions with a University of Virginia based professor. The schoolteachers from Mashamba described the challenges that their school faced daily in cooking for more than 800 students using three-stone open fires. The teachers were concerned with air pollution, which was evidenced by the dust and soot that coated the surrounding surfaces of the Mashamba Presidential Primary School. These gaseous and particulate emissions from the open fires often prevented teachers from opening the classroom windows on hot days. Cooks and students in close proximity to the open fires had reported burns and respiratory illnesses to school teachers and administrators. More specifically, the cooks reported burns to the hands and lower arms and burning eyes. At least one student fainted due to exposure to the smoke. Finally, the three-stone fire also consumed a large amount of firewood, creating an economic burden so large that children were frequently required to bring wood to school. The burden of this task on the students also increased with the expanding consumption of 
firewood; students were required to use more time searching ever more distantly for firewood as local sources were no longer easily available.

Five undergraduate, interdisciplinary University of Virginia students engaged in this dialogue initiated by the Mashamba community. They studied the issue throughout the semester as a class project. Consequently, two of the team's youngest members received funding from the Institute of Practical Ethics to conduct a site visit to Mashamba in 2009 on a volunteer basis. This research and communication with Mashamba community leaders revealed the school's potential to implement a more efficient alternative. It also launched future involvement from Mashamba community members and additional University of Virginia students.

In the summer of 2010, University of Virginia students and Mashamba Primary School faculty collaborated to design and implement a solution. With an alliance from ESAVANA, the University of Virginia students traveled to the region on a Jefferson Public Citizens grant that covered travel and living expenses and provided the students with a stipend. Catalyzed by the University of Virginia students' visit, the community adapted and implemented a Rocket Stove, which is a more efficient insulated wood-burning stove. ${ }^{\text {xii }}$ This solution is fuel-efficient, has low smoke emissions, serves as a learning tool for schoolchildren and neighboring communities, and can be constructed and maintained using local and affordable resources (Figure 1).

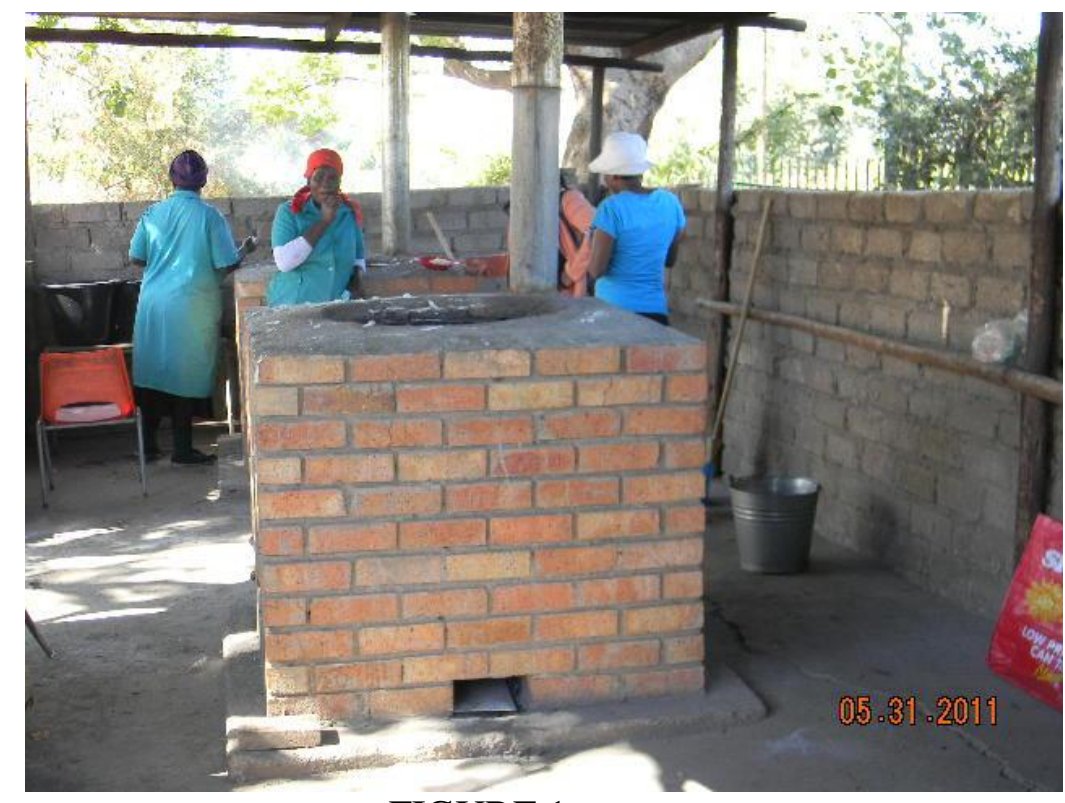

FIGURE 1

The Mashamba PRESIDENTIAL PRIMARY SCHOOL KITCHEN WITH ROCKET STOVES IN USE ONE YEAR AFTER THE FIRST STOVE WAS BUILT.

Service learning projects like this one are meaningful not only to communities, but also to university stakeholders. Communities benefit from receiving useful services and strengthening their relationships with universities. ${ }^{\text {xii }}$ At the same time, professors report greater satisfaction with student reflection, discussion, and class participation for students involved in service learning than for those who are not. ${ }^{\text {xiv }}$ Additionally, students engaged in service learning feel more connected to their universities and are more likely to graduate than students not involved in service learning. ${ }^{\mathrm{xv}}$ Beyond contributing to students' academic development, service learning 
plays an important role in students' personal and moral growth. ${ }^{\text {xvi }}$ Such evidence suggests that service learning has far-reaching impacts extending to all stakeholders. Going about service learning in a manner that builds on the strengths of a community through respect, relationships, and reciprocal learning can help ensure that these effects are positive and long lasting.

A wealth of reciprocal benefits arises when undergraduate students approach development projects as learners with plans to work with, rather than for, their community partners. ${ }^{\mathrm{xvi}}$ In this case study, a foundation of trust enabled the outside participants to act as catalysts, combining existing resources to promote sustainable solutions that benefitted the Mashamba community and the undergraduate students. ${ }^{\text {xii }}$ Through dialogue that stemmed from robust relationships, collaborators on the project gained insight into what needed to be changed, and more importantly into how the community could drive these changes by harnessing its own capital. In describing the process of community engagement in developing cookstoves, this article provides an example of how community ownership of service learning projects propels ongoing projects that can live on and grow beyond initial expectations.

Maintaining inter-personal relationships is essential throughout development projects. One conversation, one encounter, or even one extended visit has frequently been considered insufficient for the development of such relationships. ${ }^{\text {xiii }}$ Active engagement with a community and successful interaction in service learning requires a sense of reciprocity, respect, and trust amongst all parties. ${ }^{\text {xix }}$

The relationships supporting this project were formed over more than a decade through key partners from ESAVANA in the Limpopo Province of South Africa. The project's team development was fostered in two ESAVANA classes of University of Virginia students, where students connected with diverse classmates and were exposed to the ethics of community engagement and service learning. Two additional core classes within the ESAVANA network directly brought together university students and professors who shared ideas and planted the seeds for this project to grow. These students and professors, both men and women, represented countries around the world, including South Africa, Botswana, Mozambique, Mongolia, and Nepal. They specialized in disciplines including education, forestry, agricultural development, community development, systems engineering, media studies, urban and environmental planning, and civil and environmental engineering. The relationships formed through these diverse ESAVANA classes fostered a multilateral transfer of knowledge.

In the fall of 2008, an undergraduate course focused on academic community engagement, "Engineering in Community Settings," connected students from various departments under a shared interest in sustainability. As an interdisciplinary course, students exchanged ideas with others they would not normally encounter in their usual academic endeavors. Throughout the course, guest speakers represented communities with which they had longstanding relationships, and shared various opportunities for involvement. One education professor in the ESAVANA network, who has had a relationship with the Mashamba community in Venda, South Africa since 1998, particularly captivated the group of students when she shared the Mashamba School's cooking challenges. The professor provided information about the Mashamba community's deforestation and smoke inhalation concerns. With academic backgrounds in system's engineering, biomedical engineering, global development studies, and urban and environmental planning, the undergraduate team explored the issue from various dimensions through a class project. Initially, the University of Virginia students identified and researched three potential alternative cooking methods that could be more efficient and could be implemented affordably using local resources. These were the solar cooker, 
the biodigester, and a more efficient wood-burning stove. xii Subsequent courses helped develop the group's interests in energy efficiency and strengthened relationships with South African stakeholders.

Another course, an intensive intersession course entitled "Ethics, Protocols, and Practices of International Research," gave University of Virginia students and South African collaborators the opportunity to personally meet. This course comprised of United States and Southern African students and community members, and it was held over the month of January at the University of Virginia. It focused on three main components: building relationships with community partners from across the globe, understanding how research can be done around the world in an ethical manner which incorporates an entire community's values, and finally creating a proposal that accurately encompasses these aspects of development. Through daily interactions with fellow undergraduates and international partners, students carefully followed ethical protocol to create comprehensive project proposals addressing a community's expressed need. The proposed research focused on doing no harm to the community's culture or way of life and giving a community the autonomous choice to express their desires. The pedagogy of the class was based on the three "R's": Respect, Reciprocity and Relationship. ${ }^{\mathrm{xx}}$

During this course in 2009, the international collaborators, especially those from South Africa, met with the University of Virginia team to discuss protocol for reciprocal learning and community engagement in their community. Teachers from Mashamba Presidential Primary School in South Africa also participated in the U.S. based course and shared information about their school and cooking situation. These in-classroom exposure visits of on-the-ground experts facilitated conversation and dialogue that allowed the student groups to learn in a way that would have been impossible directly from a book without personal contact. The Mashamba teachers allowed the student groups to clarify understandings of opportunities for collaboration. Furthermore, the teachers facilitated a primary exchange of information that was more valuable than anything available through other sources.

Next, students from both the University of Virginia and their partnering institutions in Southern Africa furthered their learning process in the South Africa region through the 2009 ESAVANA interdisciplinary study abroad course entitled "People, Culture, and the Environment of Southern Africa." This summer course provided an intensive introduction to the region and the complexity of its physical, social, cultural, political, economic and environmental context. This experience not only had a powerful impact on the students through cultural exposure and experience with both urban and rural communities, but it also allowed for students to create new friendships and to reconnect to the existing relationships formed in January. Exposure to the community members' voices gave the students an intangible understanding of everyday interactions between inhabitants, their culture, and the ways in which they harness resources from their surrounding environment.

Finally, students who experienced "People, Culture, and the Environment of Southern Africa" returned to the United States, sharing and building upon what they had learned in another ESAVANA course entitled "Development on the Ground," that was offered through the recently launched Global Development Studies major. Consistent with aforementioned coursework, "Development on the Ground" was a class of University of Virginia students dedicated to the ethics of service learning. It provided another opportunity for students across ages and disciplines to develop a community based research project. With a better understanding of the Mashamba Primary School's situation, the team recruited a diverse, interdisciplinary group of University of Virginia students (majoring in education, environmental science, and media 
studies). These students shared expertise in areas such as curriculum development, adding an educational component to the project; resource management, bringing knowledge about energy sources; and communication, contributing greater cultural fluency throughout the study.

Most importantly, all four ESAVANA courses allowed students to be challenged in unfamiliar environments. They provided opportunities for personal growth through discussion and allowed friendships to develop outside the students' direct fields of study. The students were engaged in a completely new culture and environment, which shaped how they approached situations. This was especially valuable because community engagement research demands approaches that cut across traditional knowledge boundaries, especially those between the biophysical and social sciences. Participatory action research, in which participants are actively involved in decision making, requires engagement of stakeholders from contexts ranging across human and environmental factors ${ }^{\mathrm{xxi}}$. This course forum provided students a platform to develop ties across traditional knowledge boundaries to create a sensitive foundation for their investigations and a sustainable outlook for future research. Additionally, the courses engaged students in new cultures and environments, creating lasting impressions on their approaches to new situations. The relationships facilitated through ESAVANA helped launch this and dozens of other service learning projects in both the United States and within southern Africa. ${ }^{\text {xii }}$ The cultural exposure, relationship development, and reciprocal learning promoted by the program allow for respectful community engagement to be central in this and other service-learning projects.

ESAVANA not only provided the academic groundwork for the project but also helped bring it to fruition. The network was critical in the process of finding grant money for undergraduate students from both the United States and Southern Africa to travel together, learning about different cultures and working work with communities to understand their potential needs. With the guidance and assistance from graduate students and professors connected with ESAVANA, the team submitted successful grant proposals to the Jefferson Public Citizens Program and the Institute of Practical Ethics. Faculty within ESAVANA helped guide the project's planning stages. Once on the ground, however, the service-learning project was in the hands of the undergraduate students and the stakeholders. Throughout the process of this student led research effort, trust and respect had to be mutual for the students to work effectively with community partners.

This collaborative effort facilitated by ESAVANA created long lasting relationships that may have otherwise never existed. Because of ESAVANA's efforts, service learning projects and study abroad programs continue in Southern Africa, each time giving a new group of students a refreshed perspective on development and continuing to disseminate knowledge in both the United States and Southern Africa.

\section{Project OVerview Building Stoves With CoMmunity ENGAgement}

\section{The Three-Stone Fire}

The Mashamba Primary Presidential School typically cooked lunch for approximately 801 students over three traditional three-stone open fires (Figure 2). While three-stone open fires are often $90 \%$ efficient at turning wood into energy, only 10-40\% of released energy actually reaches the pot. ${ }^{\text {xiii }}$ 


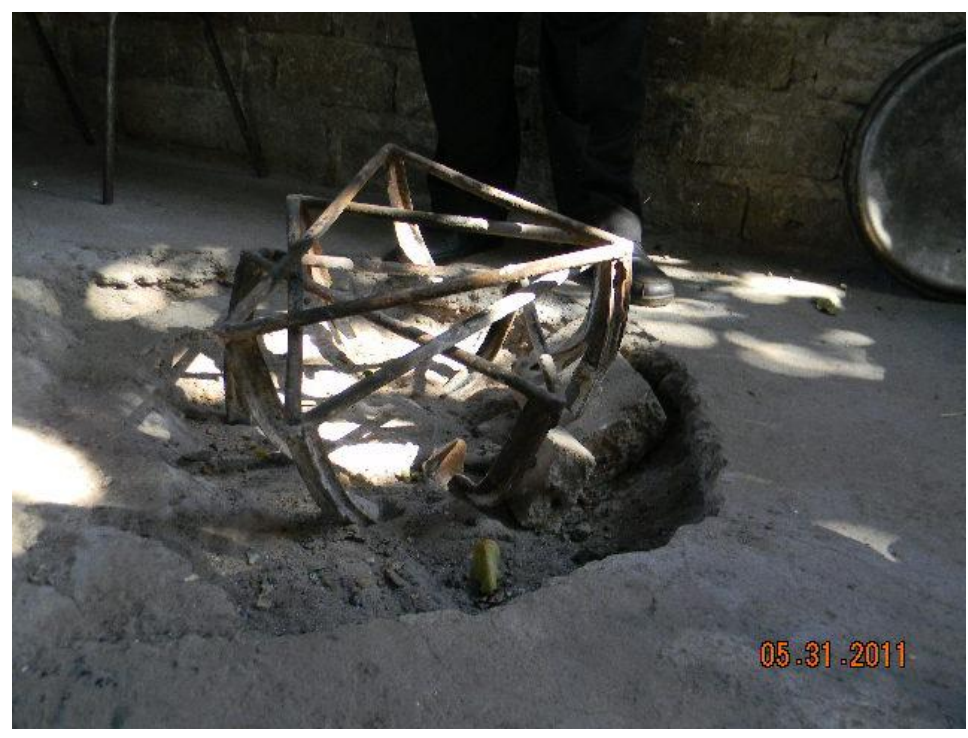

FIGURE 2

TRADITIONAL METHOD OF COOKING USING AN OPEN FIRE-ONE YEAR LATER, THIS HAD BEEN ABANDONED FOR COOKING IN THE SCHOOL, REPLACED BY ROCKET STOVES.

In 2009 a cohort of the University of Virginia students visited the Mashamba community for a week after the ESAVANA summer course, and they engaged in a dialogue to learn how the community could effectively address the community's expressed for a sustainable cooking tool. Meetings with primary school teachers, the School Governing Body, and the Tribal Council supported the students' prior learning about alternative cooking methods and reaffirmed the necessity for an economically feasible option that could be led and maintained by the Mashamba community. The visit also clarified the community's priorities and desire for the chosen solution to serve as an educational model that could be implemented elsewhere. After comparing possible solutions, the community decided that a more efficient insulated wood-burning stove met its criteria. Three industrial sized stoves would suffice to prepare lunch for 800 students. This solution was deemed cost effective, maintainable, and efficient.

\section{The Rocket Stove}

The community decided to create an enclosed wood-burning stove model based on Rocket Stove technology. The Rocket Stove, originally developed at the Aprovecho Research Center, relies on insulation for heat retention in cooking. ${ }^{\text {xxiv }}$ Improving heat transfer efficiency to the pot through this solution facilitates a significant reduction in fuel consumed. Additionally, improving fuel combustion efficiency reduces smoke and toxic emissions. Fuel use and emissions are reduced by forty to fifty percent according to laboratory and field testing of Rocket Stoves by Aprovecho Research Center and Shengzhou Stove Manufacturer. ${ }^{\mathrm{xxv}}$ The Rocket Stove in Mashamba consists of two main sections: the Lower Stove and the Upper Stove. The Lower Stove contains the Fuel Inlet where unburned fuel is placed along with an Air Inlet that allows air circulation through the stove. The Combustion Chamber is a vertical section that carries heat to the pot, which rests in a pot stabilizer in the Upper Stove. The total area of the inlets and outlets should be approximately equal so that air can flow smoothly through the fire. 


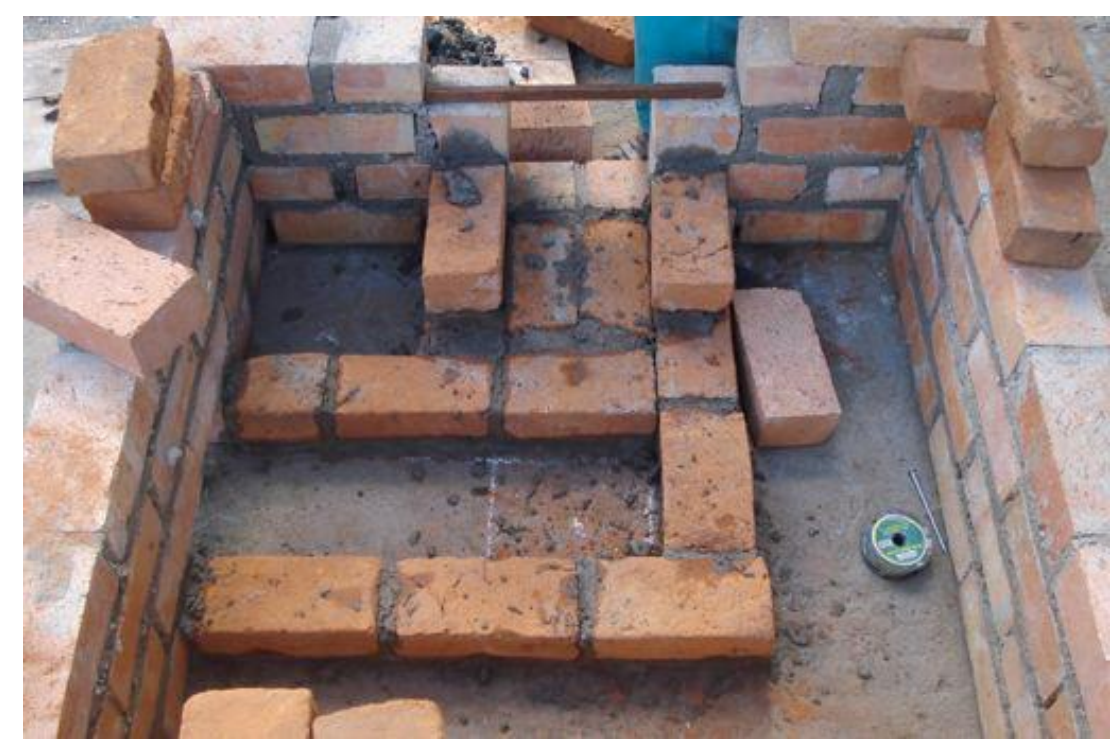

FIGURE 3

THE FIREWOOD INLET BEING BUILT EXTENDING OVER THE COMBUSTION CHAMBER AND THE AIR INLET BEING BUILT OVER THIS ${ }^{\text {XVI }}$

The Lower Outer Wall is the exterior of the lower stove and can be made out of any available bricks. This portion of the stove has two openings: the Air Inlet and the Firewood Inlet. The Air Inlet allows air into the fire to fuel it and the Firewood Inlet allows wood to enter the stove. The Air Inlet should be placed on a side where there is airflow so that air can easily enter and feed the fire. The Firewood Inlet belongs on a different wall perpendicular to the wall with the Air Inlet.

The Inner Chamber includes all parts of the stove that are inside the outer walls. The Inner Chamber contains the Air Inlet, the Firewood Inlet, and the Combustion Chamber. The Combustion Chamber is the area of the stove where the fire burns and carries heat up to the pot. This portion, excluding its base, is made using insulating bricks ( 1 part charcoal powder, 3 parts clay), which keep the heat inside the stove. Insulating mortar (4 parts clay, 1 part charcoal powder, 1 part cement) should be used to connect these bricks. 


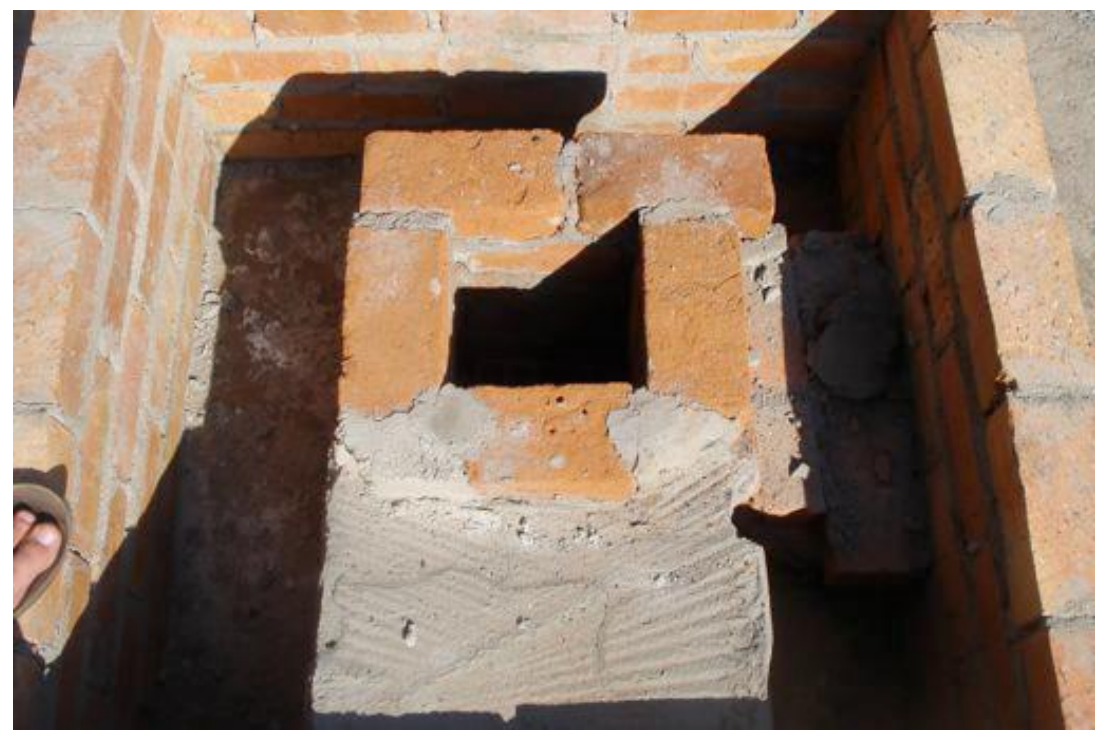

FIGURE 4

THE COMBUSTION CHAMBER BUILT WITH A SUPPORTING WALL

The Lower Stove Body is completed with a support wall behind the combustion chamber and topped with a metal grate. An area is cut out of the grate to allow space for the combustion chamber, and a metal Pot Support goes through the grate. Finally, the spaces between the Outer Walls and Inner Chambers are filled with insulation, which in this case, was ash, and the grate is covered with cement (Figure 5).

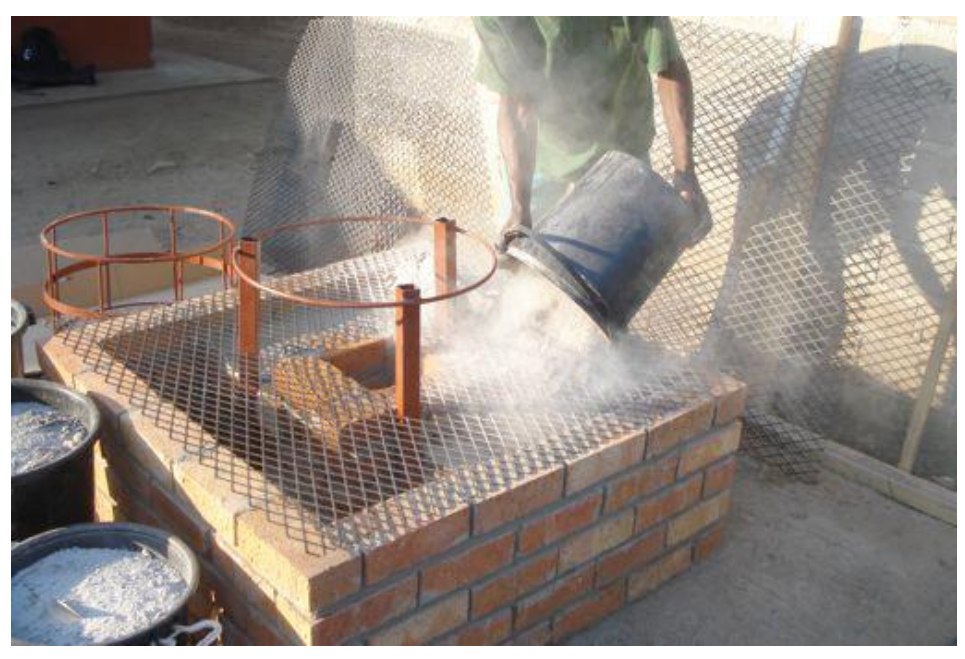

FIGURE 5

FILLING THE LOWER STOVE BODY WITH INSULATING MATERIAL (ASH). THE POT SUPPORT HAS BEEN LAID ON TOP OF THE GRATE

The Pot Skirt is built on top of the Lower Stove Body. Made of insulating bricks and insulating mortar, it surrounds the outside of the metal pot skirt stabilizer (Figure 6). The Pot Skirt insulates the pot while heating, allowing for more efficient cooking. The Upper Outer Wall 
encloses the Pot Skirt and surrounding insulation with regular bricks. A chimney goes into the Upper Stove Body to bring smoke away from the user.

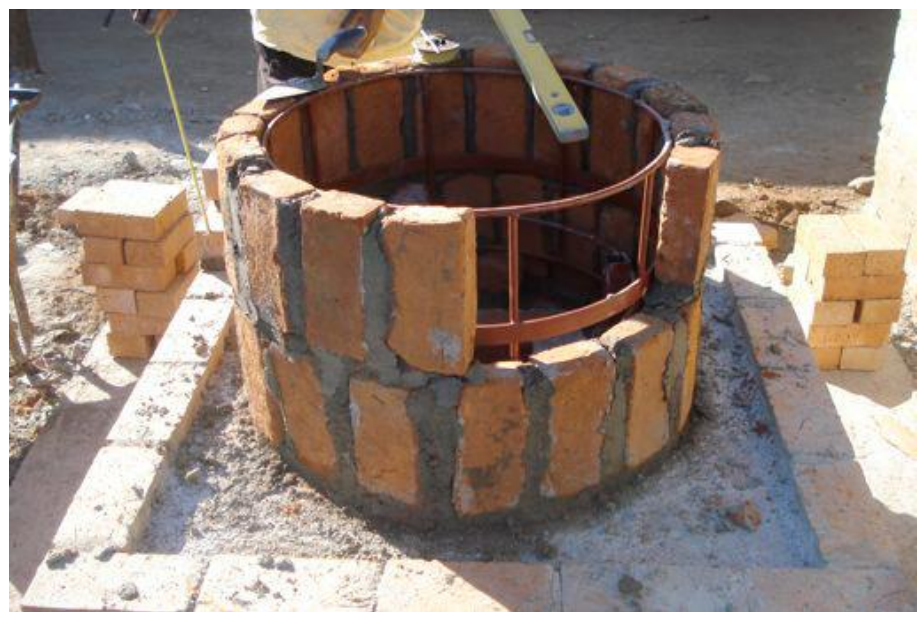

FIGURE 6

INSULATING BRICKS LAID AROUND THE POT SKIRT STABILIZER. SPACE IS LEFT IN THE SECOND LINE TO INSERT THE CHIMNEY

\section{Modifying the Rocket Stove With the Mashamba Community}

Though Rocket Stove technology had already been applied in numerous African countries such as Uganda, Lesotho, Mozambique, Malawi, Zambia, and South Africa, no industrial sized example existed near Mashamba. ${ }^{\text {xxi }}$ This created the opportunity to adapt a version specific to the Mashamba community's needs. These needs included the use of local materials and expertise in the event that modifications, maintenance, and repairs needed to be conducted. Access to local supplies of materials and expertise not only assures affordability but could also lead to sustainability by improving the resilience of the approach through the removal of necessary parts and labor from far removed locations. ${ }^{\text {xxvii }}$ To ensure that the modified Rocket Stove would incorporate local resources, skills, and priorities, the University of Virginia and Mashamba Primary Presidential School team engaged in dialogue with the greater Mashamba community. Throughout interactions from those as informal as daily conversations to official meetings, there was a constant reciprocal learning process that guided the project. While not without limitations, this exchange was the driving factor behind the project's design, implementation, maintenance, and expansion.

During the University of Virginia students' 5-week immersion into the Mashamba community, they lived with primary school teachers. The group's constant and visible presence in the community made their activities known throughout Mashamba, granting the project credibility and facilitating collaboration. The students became family members, sharing meals and personal conversations. It was through this gateway that the University of Virginia students not only learned about daily life in Mashamba, but they also learned how to navigate local hierarchies within the community. For example, they discovered the importance of transparency with the entire community in decision-making. Additionally, the students learned to communicate directly with adults rather than through their college-aged children. Though this 
protocol was time consuming to follow, it was important in the process of correct collaboration with the community. It helped them engage with groups such as the Mashamba Tribal Council and the School Governing Body in addition to local experts.

The Mashamba Tribal Council's approval was a key factor in implementing this project, and it was facilitated by pre-established relationships with community members. With guidance from their Mashamba host families, the University of Virginia students met the Tribal Council as soon as they entered the community. The students also learned to properly address the chief; for instance, they were informed that while in some parts of Limpopo women must kneel in the chief's presence, in Mashamba kneeling is welcome but not necessary. Such respectful interactions fostered a relationship with the Tribal Council that continued at future community meetings.

The School Governing Body, a Mashamba community group comprised of teachers, students, parents, and other community members, was another avenue for collaboration on this project. Meeting with this group launched community discussion about stove criteria and regarding the local skills and resources that could be leveraged during stove design and implementation. The community voiced their concerns for cost effectiveness, firewood conservation, safety, modernity, and air quality. They also had the idea of engaging primary school students in the solution, which they hoped could serve as a teaching tool to help educate their students as leaders in the field of energy efficiency.

To continue this community discussion, the researchers invited community members to drop-in meetings at the Mashamba Primary Presidential School. This form of community engagement was met with two main challenges. First, by holding office hours in the host teachers' classrooms, other teachers felt excluded. The team thus learned to put another teacher in charge of planning and communication decisions to avoid cultural misunderstandings. Second, the meetings were sparsely attended. The team later realized that members of the Mashamba community might not have been accustomed to this sort of meeting. Nevertheless, their efforts did yield some positive results. For example, one community member shared his ideas for a pot stabilizer, which was instrumental in the project's final design.

For additional input, the team sought out more individual experts, with whom they were connected through the ESAVANA network. For example, a local spiritual leader shared the Venda history of forest conservation, which gave the project cultural significance. Education experts provided useful advice on engaging schoolchildren in the project, and a local baker shared her clay oven, which demonstrated how mortar could be fired through the use of a stove. Knowledgeable figures in the region were essential in the project's cultural and technical integration with the community.

As requested by the Mashamba School Governing Body, public participation in this effort extended to primary school students. In class, the students visually represented their ideas for a sustainable cooking apparatus, many of which inspired the finished product. During the summer of 2010, Mashamba Primary School teachers designed and implemented an environmental sustainability curriculum to foster environmental problem solving among the students.

The community engagement process described above set the Mashamba community up for leadership in adapting and implementing the Rocket Stove. The University of Virginia students quickly abandoned their plans of brick making and laying, recognizing the superior skills in the community. For example, one local brick maker mastered the creation of insulating bricks. They were able to perfect a mixture of readily available clay, charcoal, and water, and 
applied their technique of shaping the bricks in wooden forms and drying them in the sun. This process overcame the challenge of making the bricks without cracking them.

Local skills were also essential for the stove's metalwork, which was sourced from a nearby artisan. A workshop in Makhado, a 40-minute drive from Mashamba, was produced customized metal pieces, including the Pot Support, Pot Skirt Stabilizer, Ash Catcher, Fuel Bed, and the Fire Tray based on the team's specifications for the school. Additional pieces invented by the community, including the Heat Shield and the Pot Removing Bars, were also created at the workshop.

All other hardware was readily available in local shops. The team learned where to find materials such as cement and metal grates in Mashamba and Makhado. They worked with shopkeepers, sharing the stove building plans with them in order to facilitate the process should it be repeated.

Local skills and resources were essential beyond the project's preparation, but also throughout the actual construction of the stoves. A Mashamba local who knew how to smoothly lay and cut bricks constructed the stove using the regional materials, Though they had other community obligations, this individual volunteered skills to this project with the hopes of applying the Rocket Stove design elsewhere in the future.

As the stove was being built, community members observed and commented on the process. Community members contributed their ideas and also learned about the alternative cooking method that could potentially be adapted elsewhere.

When the University of Virginia students' 5-week stay in Mashamba was over, the project continued. One stove was completed and tested with the community, but two more had yet to be built. Mashamba community members had full ownership over the project, and they consequently finished constructing the additional stoves themselves.

\section{Assessment of the Project Design Through Evaluation and Expansion}

Because universities, by their nature, are institutions with long lifespans that greatly exceed the average timespan of an undergraduate student education, these institutions can serve as facilities that support university-community relationships that outlast the good intentions and project lifespan of a particular student group. The combination of personal, professional and institutional relationships continues to exist long after students graduate, future generations of students build upon the work started by those before them. Lasting networks of professors, students, and communities provide the means for development projects to live on longer than otherwise. University of Virginia, founded in 1819, places a unique interest in international research programs through departments such as the Center for Global Health and Research, the Center for International Studies and the International Studies Office. Students have a range of scholarship opportunities available to them from a combination of private organizations and these departments in order to facilitate research abroad. ${ }^{\text {xviii }}$ In parallel, the Global Development Studies major at University of Virginia is an interdisciplinary academic program focusing on social justice, sustainable economic development, public health, global interconnection and public service. Graduate students and teachers within the department support undergraduate research projects and encourage students to develop critical skills assessing development projects. Many international research projects at University of Virginia take place through existing relationships and facilitative networks, and in the case of this project, the ESAVANA network provided the backbone of this project. 
Because of ESAVANA's longstanding relationship with the Mashamba community and the interest of a new group of undergraduate students, this project was evaluated a year later during the summer study abroad program. Despite a short notice of visitation to the Mashamba Primary Presidential School, the students were greeted warmly and professionally (Figure 7). Instantly, a connection was made between two groups of relative strangers as the director of Mashamba stood up and said, "Welcome home." Immediately, students identified the importance of fostering and maintaining relationships.

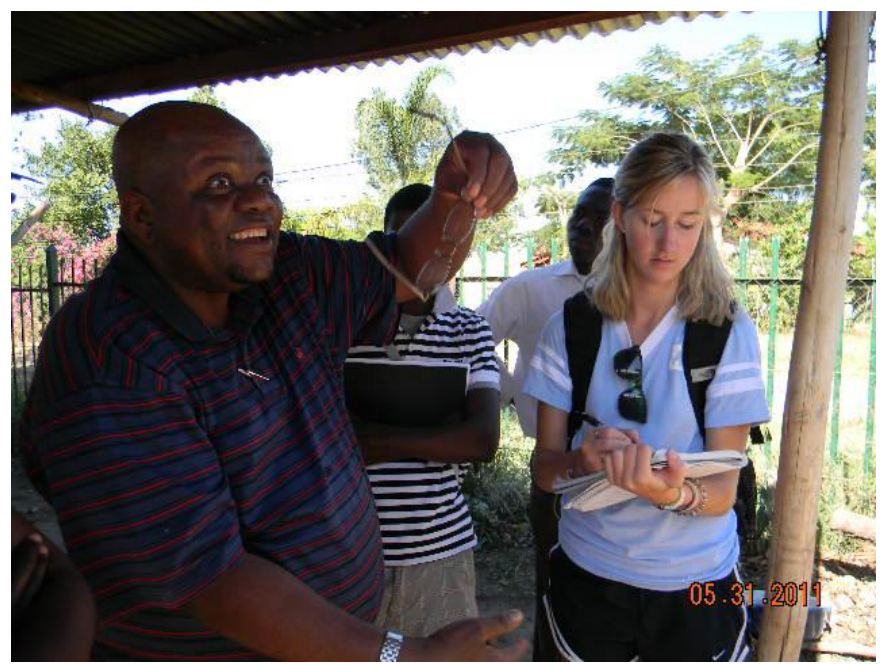

FIGURE 7

A MASHAMBA SCHOOL TEACHER DESCRIBING THE STOVES TO THE NEW CONTINGENT OF ESAVANA STUDENTS WHO STAND IN THE MASHAMBA KITCHEN TAKING NOTES.

Upon entering the community, the group found three working stoves. The student evaluators discovered that through using the modified Rocket Stoves, the school reduced its fuel wood consumption from two truckloads per month to one truckload approximately every five weeks, roughly a $40 \%$ reduction. This not only addresses the concern of deforestation, but it also saves the Mashamba Primary Presidential School approximately $\$ 100$ per month. This monthly savings frees resources and allows the school to meet its other needs. The school can allocate its money toward whatever it sees most pressing. In one particular instance, Mashamba allocated money to develop a school garden to produce lunch ingredients locally. Additionally, the reduction in heat dissipation and improvement in fuel efficiency eliminated the need for children to bring wood on their way to school (Figure 8). Moreover, the cooking time was reduced from 4.5 hours to 2 hours, allowing the cooks more time to spend ensuring the cleanliness of the school. 


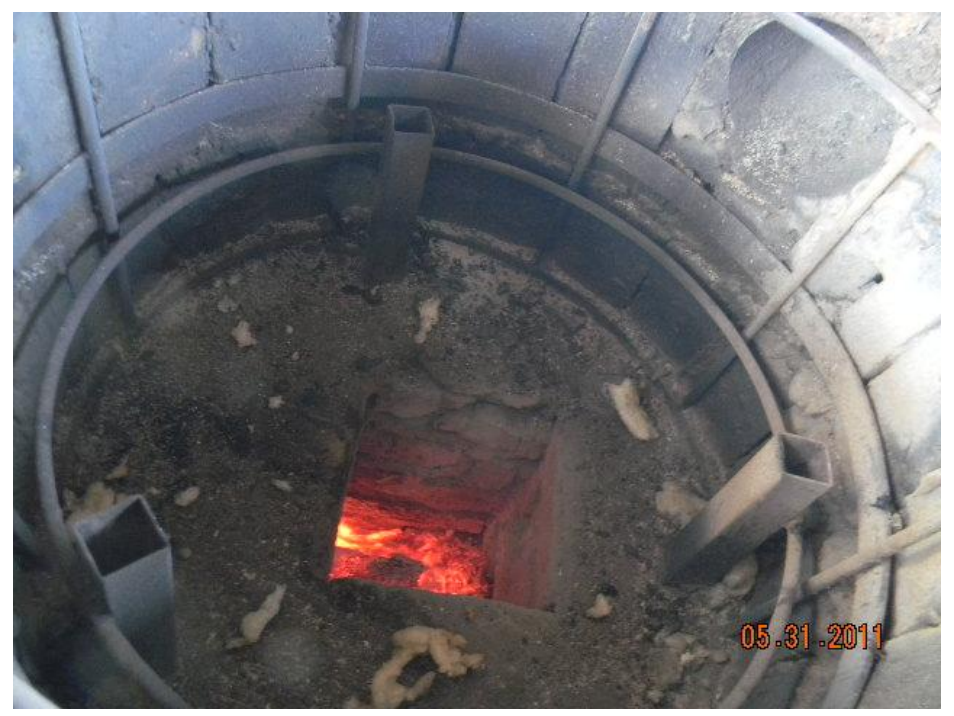

FIGURE 8

\section{CONCENTRATED HEAT IMPROVING THE FUEL EFFICIENCY OF THE NEW STOVES}

Because the cookstove has a higher temperature burn than the prior method of cooking over open fire, stove emits less incomplete carbon smoke emissions and the air quality surrounding the cooking area is subsequently enhanced. Teachers at Mashamba, in the classrooms near the cooking area can now open their windows without letting smoke in and causing discomfort. The insulated stove design prevents burns because no hot metal is exposed. The ashtray in the stoves has also significantly simplified clean up for the cooks. Additionally, the stove features increased stability and leverage as opposed to the wire construct used for cooking before. This is especially important in ensuring safety of the cooks during the cooking of pap, one of the staple foods made in Venda, which requires vigorous arm movements (Figure 9). 


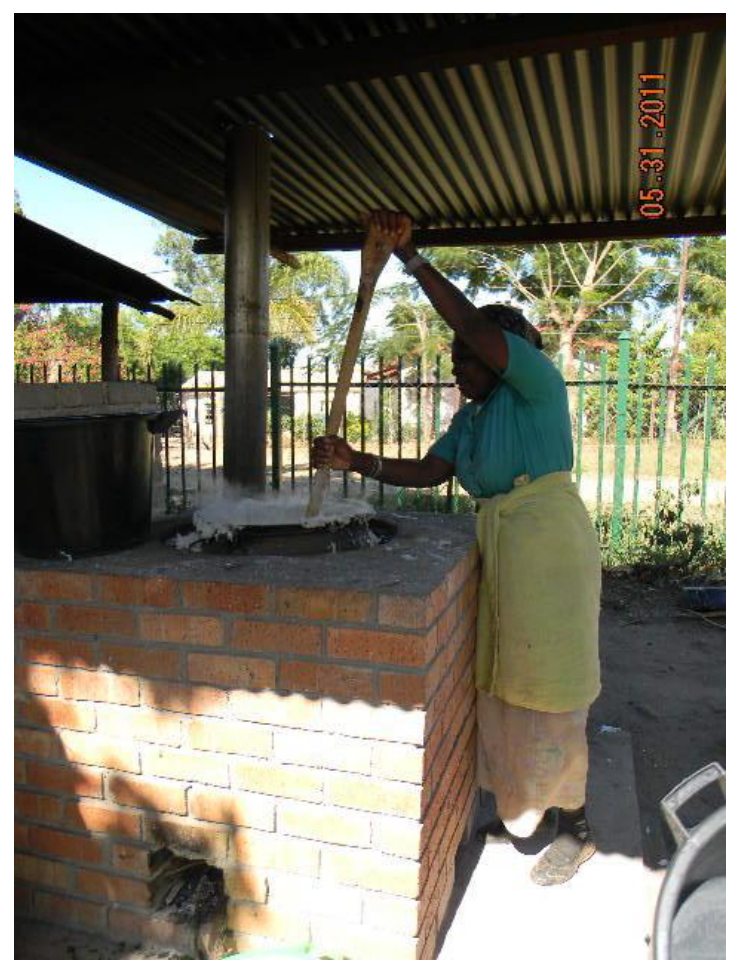

FIGURE 9

A MEMBER OF THE MASHAMBA PRIMARY SCHOOL COOKING STAFF DEMONSTRATING THE VIGOROUS ARM MOVEMENTS REQUIRED IN MAKING CORN PORRIDGE (PAP)

Most importantly, the evaluation team found that Mashamba Primary Presidential School administrators took pride and ownership in the Rocket Stoves. News of the stoves was encouraging collaboration among nearby communities. The Mashamba Primary Presidential School faculty had scheduled visits from school board members from neighboring schools who wanted to learn about the stoves and evaluate the feasibility of installing them in their own schools. The school possessed detailed plans for the stove so that other communities could replicate it. Thus, the school helped their surrounding community become aware of the simple, locally available clean cookstove technology.

In assessing areas in which the stove could improve, the student evaluators observed that the area around the stoves was covered in soot. This dust filled the air and entered the food. Furthermore, the cooks mentioned that this was a concern because it was difficult to cook while surrounded in dust. They voiced a need for an enclosure around the stove to reduce exposure to the dust. Mashamba Primary Presidential School administrators mentioned that such a project was already underway and the school was waiting to hear back from funding sources.

The student evaluators also noticed that the cooks were standing on unstable chairs while cooking and serving the students' meals. The cooks expressed that this made them feel uncomfortable and unsafe as they were often using broken chairs. The University of Virginia students along with the Mashamba faculty and staff found that modifying the stove design to include solid brick a step stool that would not block the vents of the stove could eliminate this problem. 


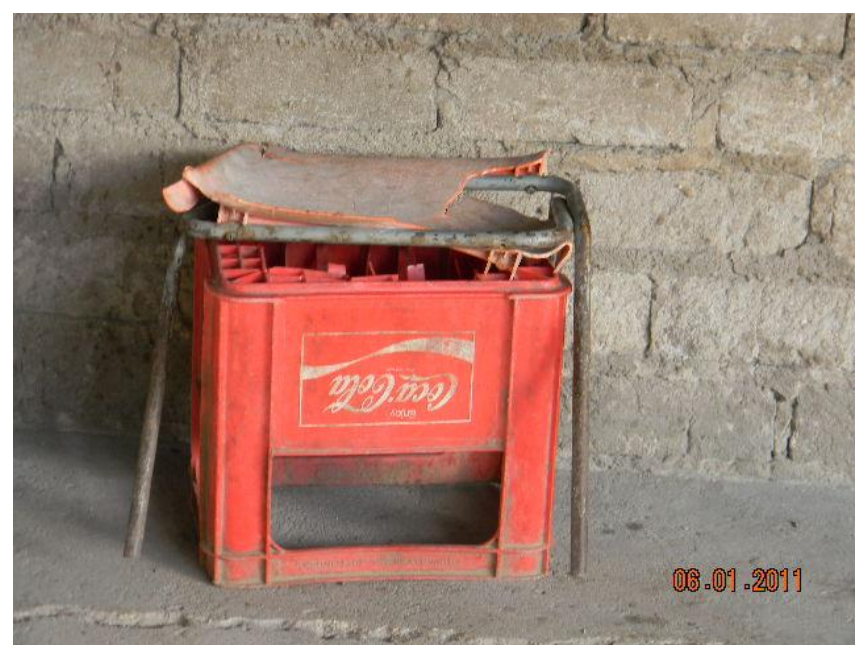

FIGURE 10

\section{AN EXAMPLE OF BROKEN AND UNSTEADY STOOLS USED TO STAND ON WHILE COOKING}

The project is still expanding. Taking into account the project evaluations, the study abroad students made copies of the stove design manual and delivered it to Mozambique and other locations in Limpopo, Mpumalanga and Bushbuckridge so that the project could be transferred. In continuing the University's engaged scholarship with the rural communities in the regions of Limpopo and Mpumalanga, South Africa, a group of undergraduate students from the University of Virginia have been actively seeking funding to travel back to Mashamba and Bushbuckridge. Their main research goal is to assess the financial, social, and environmental impacts of the rocket stoves placed in Mashamba two years ago, and to evaluate the potential implications the stoves could have during the transfer of knowledge to other schools and community centers in the Mpumalanga region. The student research team's goal is twofold. During the first phase, they hope to assess how the rocket stoves have impacted the Mashamba community through financial, social, and environmental perspectives. In the second phase, the group hopes to work with local entrepreneurs and university students from South Africa in order to disseminate the knowledge gained through participatory engagement in Mashamba to the region of Bushbuckridge.

Through this next step, the group of undergraduates hopes to rekindle established relationships while empowering individuals through access of knowledge and learning in action. By putting the community's expressed needs first, and by creating reciprocal relationships in which particular ideas, new perspectives, and the facilitation of dialogue are highlighted as a central facet, the team hopes to help ignite a sustainable solution for clean cookstoves in rural Southern Africa.

\section{CONCLUSION}

Universities can incubate relationships with communities, enabling strong development projects with reciprocal benefits. From onset to evaluation, this project's success relied on such existing partnerships between a university in the United States and various universities and communities in Southern Africa. These partnerships, over a decade old, laid the foundation for open 
communication, trust, and reciprocal learning. As a result, an established network enabled people, knowledge, and resources formed a sustainable project with long-term positive impacts for both the university and the community stakeholders.

For the university students, exposure to innovative approaches with the freedom to intelligently borrow from them was clearly important throughout the development, implementation, and evaluation of the Rocket Stove project. While the university students brought knowledge from the Aprovecho Research Center and their various academic backgrounds, the mutual learning process included harnessing local resources, ideas, and abilities. This ensured the project's effectiveness and longevity. Focusing on a community's strengths rather than its needs also reveals how communities like Mashamba can be agents of their own change. ${ }^{\text {xix }}$ The university setting fostered this approach not only by preparing students culturally and academically, but also by incubating long term-relationships with the partner community. Truly understanding a community's capacities requires respectful dialogue possible through equal partnerships. ${ }^{\mathrm{xx}}$ These connections establish the kind of trust that was essential throughout the process of identifying Mashamba's capital, exchanging ideas to develop an innovative solution, and evaluating and replicating the project.

Throughout project design, implementation, evaluation, and replication, the university provides a constant supply of students willing to engage in service learning and to carry on this established project (Figure 11). One by one, the tapestry of knowledge expands as more people become involved and more relationships are included.

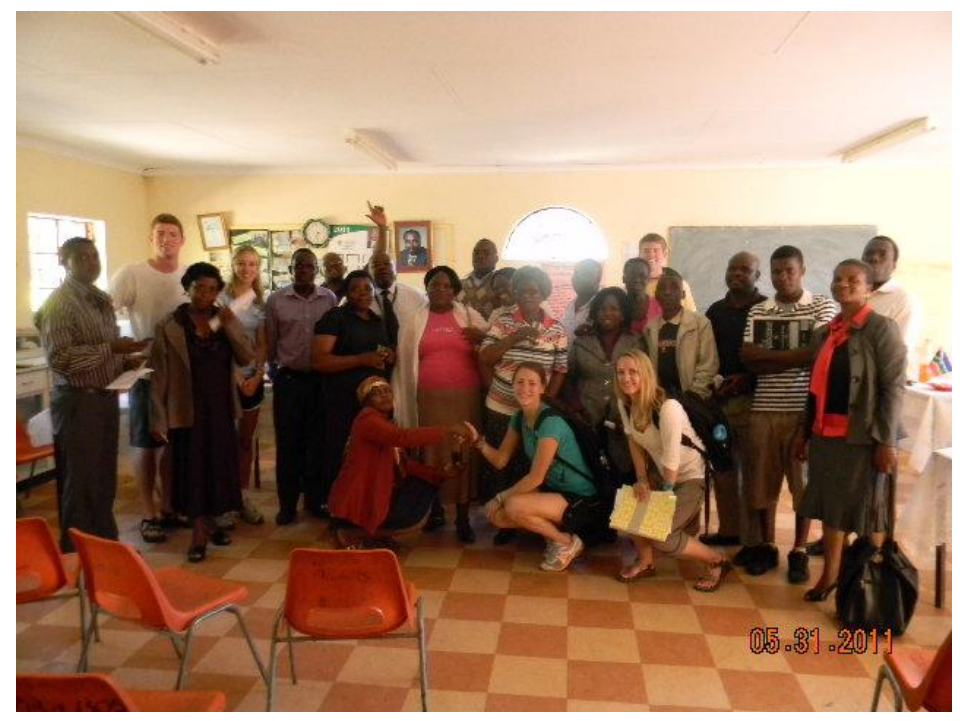

FIGURE 11

SAYING “GOODBYE FOR NOW” AFTER THE EVALUATION

The university can provide an ideal setting for service-learning projects to succeed and grow over time by providing academic preparation, linkages to relationships and resources, and an outlet for projects to be carried into the future. 


\section{ACKNOWLEDGMENTS}

The authors extend gratitude to their faculty advisors, Professor Carol Anne Spreen and Professor Robert Swap from the University of Virginia. They also thank partners Errol Mudau, Selina Mbedzi, and Alex Mashamba, and to all of the teachers at the Mashamba Primary Presidential School. Additionally, contributions from Anne Rasmussen, Katelyn Mason, Deanna Vogt, Matthew Baer, Jessica Rothbart, Whitney Morgan, Katherine Wadsworth, Miriam, Dr. Dima, Caroline Nukari, Retha Henning, Joel Mushaku, Peter Scott, Duncan Nengwenani, and the University of Venda Global Sustainability Club were invaluable. Financial support was received from the University of Virginia Jefferson Public Citizens and the Institute of Practical Ethics. ESAVANA Students on the 2011 Stove Evaluation team included Lauren Alwine, Michael Bugas, Haleigh Harper, Raleigh Hazel, Emily Hearle, Ornelio Nhaduco, Wametsi Obonetse and Shreya Soni.

\section{ENDNOTES AND REFERENCES}

${ }^{\mathrm{i}}$ WHO. (2011). Household cookstoves, environment, health, and climate change. (p. 7). Washington, DC: The International Bank for Reconstruction and Development. Retrieved from http://climatechange.worldbank.org/sites/default/files/documents/Household Cookstoves-web.pdf

${ }^{i i}$ Martin, W. J., Glass, R. I., Balbus, J. M., \& Collins, F. S. (2011). A Major Environmental Cause of Death. Science, 334(6053), 180-181. Retrieved from http://www.sciencemag.org/content/334/6053/180

${ }^{\text {iii }}$ WHO. (2011). Household cookstoves, environment, health, and climate change. (p. 10). Washington, DC: The International Bank for Reconstruction and Development. Retrieved from http://climatechange.worldbank.org/sites/default/files/documents/Household Cookstoves-web.pdf

${ }^{\text {iv }}$ The World Bank. (2011). Household cookstoves, environment, health, and climate change. (p. 13). Washington, DC: The International Bank for Reconstruction and Development. Retrieved from http://climatechange.worldbank.org/sites/default/files/documents/Household Cookstoves-web.pdf

${ }^{v}$ Martin, W. J., Glass, R. I., Balbus, J. M., \& Collins, F. S. (2011). A Major Environmental Cause of Death. Science, 334(6053), 180-181. Retrieved from http://www.sciencemag.org/content/334/6053/180

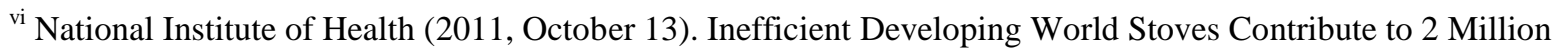
Deaths a Year. NIH News. Retrieved July 21, 2012, from http://www.nichd.nih.gov/news/releases/101311developing-world-stoves.cfm

vii The World Bank. (2011). Household cookstoves, environment, health, and climate change. (p. 14). Washington, DC: The International Bank for Reconstruction and Development. Retrieved from http://climatechange.worldbank.org/sites/default/files/documents/Household Cookstoves-web.pdf

viii The World Bank. (2011). Household cookstoves, environment, health, and climate change. (p. 12). Washington, DC: The International Bank for Reconstruction and Development. Retrieved from http://climatechange.worldbank.org/sites/default/files/documents/Household Cookstoves-web.pdf

${ }^{\text {ix }}$ United Nations Foundations. (2011, November). Igniting Change: A Strategy for Universal Adoption of Clean Cookstoves and Fuels. Global Alliance for Clean Cookstoves. Retrieved July 21, 2012, from http://www.cleancookstoves.org/resources/fact-sheets/ignitingchange.pdf

${ }^{x}$ Brown-Glazner, R., Gutierrez, V., \& Heil, E. (2010). Engaging People, Not Projects: Redifining the standards of service learning through a community led project in Tshapasha, South Africa. The Virginia Policy Review, 3(3), 5-9. 
${ }^{x i}$ Heil, E. K., \& Nengwenani, D. (2010). Student-led, Community Driven Improvement of the Drinking Supply in a Rural Village in South Africa.. International Journal for Service Learning in Engineering, 5(1), 94-110.

${ }^{\text {xii }}$ Mason, K. E., de Chastonay, A. C., Rasmussen, A. E., Baer, M. H., Rothbart, J. A., Vogt, D. C., \& Spreen, C. A. (2011). Active Engagement: Building Sustainable Stoves and Relationships in Mashamba, South Africa. Public, 2(1), 86-93. Retrieved from http://www.virginia.edu/jpc/docs/2011-JPCJournalFinal.pdf

xiii Clarke, M. M. (2000). Evaluating the Community Impact of Service Initiatives: The 3-I Model. Unpublished Dissertation, Peabody College, Vanderbilt University.

${ }^{\text {xiv }}$ Berson, J. S., \& Younkin, W. F. (1998). Doing Well by Doing Good: A Study of the Effects of a ServiceLearning Experience on Student Success. Paper presented at the American Society of Higher Education, Miami, FL.

${ }^{x v}$ Astin, A. W., Sax, L. J., \& Avalos, J. (1999). Long Term Effects of Volunteerism During the Undergraduate Years. Review of Higher Education, 22(2), 187-202.

${ }^{\mathrm{xvi}}$ Eyler, J. S. \& Giles, D. E., Jr. (1999). Where's the Learning in Service-Learning? San Francisco, CA: Jossey-Bass, Inc.

${ }^{\text {xvii }}$ Chambers, R. (1983). Rural Development: Putting the Last First. (1st ed., Vol. 1, pp. 1-256). London, England: Longman.

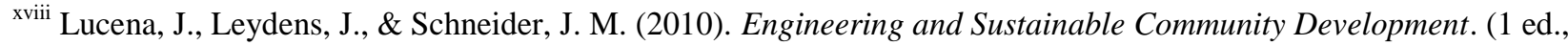
Vol. 1, pp. 1-232). San Rafael, CA: Morgan and Claypool Publishers.

${ }^{\text {xix }}$ Clayton, P., Bringle, R., Senor, B., Hug, J. \& Morrison, M. (2010). Differentiating and Assessing Relationships in Service-Learning and Civic Engagement: Exploitative, Transactional, or Transformational. Michigan Journal of Community Service Learning. pg. 5-22.

${ }^{x x}$ Harshfield, E., Jemec, A., Makhado, O., \& Ramarumo, E. (2009). Water Purification in Rural South Africa: Ethical Analysis and Reflections on Collaborative Community Engagement Projects in Engineering. International Journal for Service Learning in Engineering, 4(1), 1-14. Retrieved from http://www.virginia.edu/jpc/docs/WaterPurificationSouthAfrica2010.pdfonal

${ }^{x x i}$ Parkes, M., Panelli, R. (2001 June). Integrating Catchment Ecosystems and Community Health: The Value of Participatory Action Research. (Vol.7, pp. 85-106). Wiley Publishers. Retrieved from: http://onlinelibrary.wiley.com/doi/10.1046/j.1526-0992.2001.007002085.x/full

xxii ESAVANA. Respect, relationship and reciprocity. In Research Projects. Retrieved August 9, 2012, from http://esavana.org/.

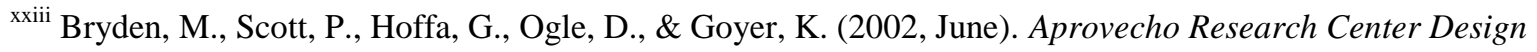
Publications: Design Principles for Wood Burning Cookstoves. Retrieved from http://www.aprovecho.org/lab/pubs/arcpubs/

${ }^{\text {xxiv }}$ Bryden, M., Still, D., Ogle, D., \& MacCarty, N. (2005, June). Aprovecho Research Center Design Publications: Designing Improved Wood Burning Stoves. Retrieved from http://www.aprovecho.org/lab/pubs/arcpubs/

\section{${ }^{\mathrm{xxv}}$ Retrieved from http://www.aprovecho.org/lab/stovetec-story/makingstoves}

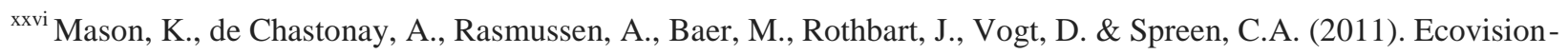
Active Engagement: Building Sustainable Stoves and Relationships in Mashamba, South Africa. Jefferson Public Citizens Journal 2011. pp. 87-94. Retrieved from http://www.virginia.edu/jpc/journal.html 
${ }^{x x v i i}$ Francis, J. \& Mudau, J.M. (2012) Strengthening the Implementation Antipoverty Strategies and the Active Role of Stakeholders: A Case Study of Mutale Municipality Community Engagement. Pretoria, South Africa: Africa Institute of South Africa. Retrieved from:

http://books.google.com/books?hl=en\&lr=\&id=wDgV6O7dKK8C\&oi=fnd\&pg=PA25\&dq=joseph+francis+universi ty+of+venda\&ots=cTSb_w_GCA\&sig=PzwybL4Euz8ZmN6K_1koB_YTW_I\#v=onepage\&q\&f=false

${ }^{\text {xxviii }}$ Retrieved from http://www.virginia.edu/iso/issp/NewWindows/funding.html.

${ }^{\text {xxix }}$ Mathie, A., \& Cunningham, G. (2003). From clients to citizens: Asset-based community development as a strategy for community-driven development. Development in Practice, 13(5), 474-486

${ }^{\mathrm{xxx}}$ Chambers, R. (1997). Whose Reality Counts? Putting the First Last. (1st ed., Vol. 1, pp. 1-297). London, England: Intermediate Technology Publications. 